\title{
An Overview of Cancer Prevention: Chemoprevention and Immunoprevention
}

\author{
Kyle J. Gu' ${ }^{1,2}$, Guojun $\mathrm{Li}^{1,3}$ \\ ${ }^{1}$ Department of Head and Neck Surgery, The University of Texas MD Anderson Cancer Center, Houston, TX, ${ }^{2}$ College of \\ Natural Sciences, The University of Texas at Austin, Austin, TX, ${ }^{3}$ Division of Epidemiology, The University of Texas School \\ of Public Health, Houston, TX, USA
}

\begin{abstract}
Cancer prevention encompasses a broad spectrum of strategies designed to lower the chance of developing cancer and reduce the morbidity of established cancer. There are three levels of cancer prevention. Eliminating or mitigating cancer risk factors by adopting healthy behaviors and lifestyles, such as avoiding tobacco and alcohol use, exercising, eating a healthy diet, and applying sunscreen to protect against UV exposure, belongs to primary prevention and is the easiest and most effective way of preventing cancer for the general public. Secondary prevention includes screening to identify precancerous lesions and taking intervention measures to prevent disease progression to malignancy. Tertiary prevention refers to reducing or controlling the symptoms and morbidity of established cancer or the morbidity caused by cancer therapy. For high-risk populations, chemopreventive agents, such as selective estrogen receptor modulators (including tamoxifan and raloxifene) in breast cancer prevention and non-steroidal anti-inflammatory drugs (aspirin) in colorectal cancer prevention, and immunoprevention using human papillomavirus and hepatitis $B$ virus vaccines in infection-related cancers have shown clear clinical benefits of reducing cancer incidences. In this review, we will summarize the current status of cancer prevention, focusing on the major agents that are clinically used for chemoprevention and immunoprevention.
\end{abstract}

Key Words Chemoprevention, Immunoprevention, Selective estrogen receptor modulators, Non-steroidal anti-inflammatory agents, Vaccines

\section{INTRODUCTION}

Cancer is the second leading global cause of death, responsible for 1 in 6 deaths [1]. About $38.4 \%$ of people in the world will be diagnosed with cancer at some stage in their lifetimes, and roughly 1 out of every 3 Americans will develop a malignancy [2]. Given the prevalence and severity of cancer worldwide, enormous resources and efforts have been devoted to improve cancer screening, diagnosis, and treatment. The progress in the war against cancer has been quite effective, as the cancer death rate in the United States has dropped by $29 \%$ from 1991 to 2017 [2].

Despite considerable progress in cancer therapies such as targeted therapy and immunotherapy, the prognosis of many advanced cancers is still dismal. Effective cancer screening and early detection offer the best hope of further reducing cancer mortality. However, only a few cancer screening tests, for instances, in cervical, breast and colon cancers, are routinely used in clinics and proven to reduce cancer mortality. While cancer treatment is largely ineffective against advanced cancer, and cancer screening is only available for a few cancers, cancer prevention serves as an undervalued approach to reduce cancer incidence and mortality that must be given more attention.

There are three levels of cancer prevention [3,4]. Primary prevention refers to decreasing cancer incidence by eliminating risk factors for cancer, such as exercising, eating a healthy diet, and avoiding tobacco smoke and alcohol drinking [5]. Secondary prevention includes screening to identify diseases in the earliest stages (e.g., preneoplastic lesions) and blocking disease from progressing to malignancy. Tertiary prevention refers to reducing or controlling the symptoms and morbidity of established cancer or the morbidity caused by cancer therapy. Implementing drugs into the body to pre-

Received June 21, 2020, Revised August 4, 2020, Accepted August 14, 2020

Correspondence to Guojun Li, E-mail: gli@mdanderson.org, https://orcid.org/0000-0001-9505-1502

Check for updates

(i) This is an Open Access article distributed under the terms of the Creative Commons Attribution Non-Commercial License, which permits unrestricted noncommercial use, distribution, and reproduction in any medium, provided the original work is properly cited.

Copyright $\odot 2020$ Korean Society of Cancer Prevention 
vent tumor onset, malignant progression, or recurrence is known as chemoprevention. While certain chemopreventive agents such as tamoxifan and aspirin have been effective in reducing cancer risks, their intake remains low due to concerns of long-term side effects $[3,4,6]$. Moreover, cancer cells adapt in an evolutionary continuum in response to attempts to control them, while chemopreventive medicine is stagnant in nature. In this regard, immunotherapy has garnered the attention of researchers who seek to utilize the immune system as an adaptive entity that can respond to cancer's evolution, potentiating immunoprevention as a more efficacious approach in preventing carcinogenesis [7-10]. With the success of vaccines against virally induced cancers, recent progress in the identification of candidate tumor antigens for non-viral cancers, and the application of immune checkpoint inhibitors in premalignant lesions, immunoprevention is rising in popularity and serves as the future of cancer prevention [7-10].

\section{CHEMOPREVENTION}

Chemoprevention involves the input of external agents such as medication or supplements to inhibit or delay the onset, progression, or recurrence of cancer. Several agents have been approved by United States Food and Drug Administration (FDA) for clinical use in the setting of cancer prevention [3]. Table 1 summarizes the chemopreventive agents that are discussed in this article.

\section{Selective estrogen receptor modulators (SERMIs)}

Tamoxifen was the first FDA-approved chemopreventive agent, which can reduce the risk of estrogen receptor (ER)-positive breast cancer [6]. The second generation SERM, raloxifene, was also approved by FDA for preventing breast cancer in high-risk populations [6]. Several United States and European phase III cancer prevention trials showed that tamoxifen reduced the risks of ER-positive breast cancer by $30 \%$ to $60 \%$ in both pre- and post-menopausal women at high-risk of breast cancer [11-15]. The United States Preventive Services Task Force (USPSTF) conducted a systematic review of trials and estimated that compared with placebo, tamoxifen reduced the incidence of invasive breast cancer by 7 events $(95 \% \mathrm{Cl}, 4-12)$ per 1,000 women over 5 years [16]. However, tamoxifen use was associated with increased risks of venous thromboembolic events (e.g., stroke, pulmonary embolus, and deep vein thrombosis), cataract, endometrial cancer, and vasomotor symptoms [16]. The second generation SERM, raloxifene, produced similar preventive effect on ER-positive breast cancer, and was associated with lower side effects than tamoxifen use $[17,18]$. FDA approved both drugs for breast cancer prevention in high-risk individuals.

In addition to SERMs, two aromatase inhibitors (Als), exemestane and anastrozole, have also been shown to significantly reduce ER-positive breast cancer incidence in randomized clinical trials in high-risk post-menopausal women $[19,20]$. Als block the enzyme aromatase and hence inhibit the conversion of androgen into estrogen. Als produced stronger efficacy and had more favorable side effect profiles than SERMs [16]. The USPSTF recommends that clinicians offer to prescribe risk-reducing drugs, including tamoxifen, raloxifene, or Als, to women who are at increased risk for breast cancer and at low risk for adverse side effects [16].

\section{Non-steroidal anti-inflammatory drugs (NSAIDs)}

Due to the link between inflammation and cancer development, NSAIDs and COX2 selective inhibitors (COXIBs), have been utilized as chemopreventive agents [21-23]. A large multitude of evidence including observational studies and randomized controlled clinical trials have substantiated that aspirin use can decrease the incidence and mortality of colorectal cancer (CRC) within the general population, while less extensive studies have indicated reductions in incidence

Table 1. Summary of major chemopreventive agents

\begin{tabular}{|c|c|c|c|}
\hline Agent & Target & Cancer prevention effect & References \\
\hline $\begin{array}{l}\text { Selective estrogen receptor } \\
\text { modulators }\end{array}$ & Estrogen receptor (ER) & $\begin{array}{l}\text { Reduce ER-positive breast cancer } \\
\text { incidence in high-risk populations }\end{array}$ & $11-18$ \\
\hline Aromatase inhibitors & Aromatase & $\begin{array}{l}\text { Reduce ER-positive breast cancer } \\
\text { incidence in high-risk populations }\end{array}$ & $16,19,20$ \\
\hline $\begin{array}{l}\text { Non-steroidal anti- } \\
\text { inflammatory drugs }\end{array}$ & COX1/COX2 & $\begin{array}{l}\text { Reduce the occurrence of several } \\
\text { cancers, mainly CRC and less notably } \\
\text { stomach and esophageal cancers }\end{array}$ & $21-25$ \\
\hline Statins & HMG-CoA reductase & $\begin{array}{l}\text { Observational studies showed long } \\
\text { term statin use reduces incidences of } \\
\text { gastrointestinal cancer }\end{array}$ & $27-30$ \\
\hline Metformin & Gluconeogenesis & $\begin{array}{l}\text { Observational studies showed metformin } \\
\text { use lowers risks of cancer incidence and } \\
\text { mortality in diabetic patients }\end{array}$ & $31-34$ \\
\hline
\end{tabular}

CRC, colorectal cancer; HMG-CoA, 3-hydroxy-3-methylglutaryl coenzyme A. 
for stomach and esophageal cancers, although smaller in magnitude [21-23].

There are several proposed mechanisms through which NSAIDs and COXIBs are hypothesized to lower the risk of $\mathrm{CRC}$. The most compelling mechanism involves the ability of the chemopreventive agents to inhibit COX2, an enzyme involved in the synthesis of inflammatory prostaglandins that stimulate cell proliferation and inflammation [24,25]. COX2 is overexpressed in early stage colon carcinogenesis and colorectal adenomas and increases resistance to apoptosis and promotes angiogenesis. By inhibiting COX2 enzyme, NSAIDs and COXIBs decrease the production of inflammatory prostaglandins, therevy inhibit the downstream tumor-promoting events such as inflammation, cell proliferation, and angiogenesis, and prevent cancer initiation (Fig. 1). Most NSAIDs inhibit both COX1 and COX2, whereas COXIBs selectively inhibit COX2.

Although aspirin, as the most prominent NSAID, has been the poster child in the chemopreventive approach to fighting $\mathrm{CRC}$ and other types of cancer, much remains to be clarified regarding the optimal dosage and duration for its use. While daily doses of $75 \mathrm{mg}$ and above have reduced long-term incidence of $7 \%$ to $10 \%$, there is no definitive proof of increased reduction with higher dosages [22]. The harmful side effects of long-term use of aspirin including gastrointestinal ulcerations and cardiovascular toxicities have impacted the uptake and adherence of aspirin use. The USPSTF recommends initiating low-dose aspirin use for the primary prevention of cardiovascular disease (CVD) and CRC in adults aged 50 to 59 years who have a $10 \%$ or greater 10 -year CVD risk, a life expectancy of at least 10 years, and are not associated with higher risk of bleeding [26].

Aspirin inhibits both COX1 and COX2. COXIBs selectively inhibit COX2. Celecoxib (celebrex) is the most well-studied COXIB and has demonstrated efficacy in randomized clinical trials for $\mathrm{CRC}$ prevention in high risk population [3]. Celecoxib was approved by the United States FDA as an oral adjunct to usual care for patients with familial adenomatous polyposis

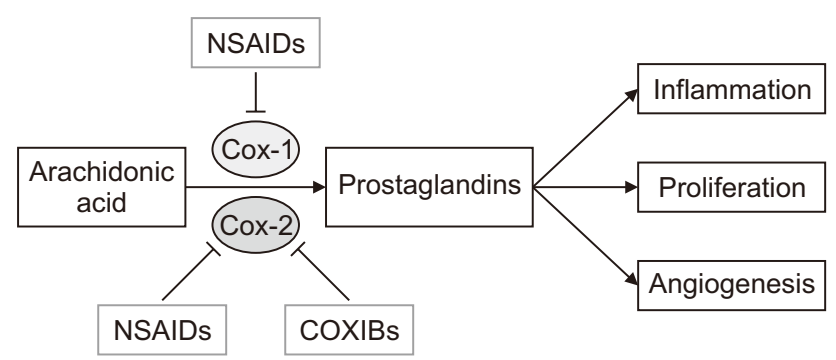

Figure 1. A simplified view of the biological mechanisms of nonsteroidal anti-inflammatory drugs (NSAIDs) and COX2 selective inhibitors (COXIBs). NSAIDs and COXIBs inhibit COX1/2 enzymes and block the synthesis of inflammatory prostaglandins, therefore inhibit the downstream tumor-promoting events, such as inflammation, cell proliferation, and angiogenesis, and prevent cancer initiation.
(FAP), a rare hereditary disease that has a high likelihood of developing CRC. Celecoxib was the first pharmacological agent to be used for reducing the risk of adenomatous colorectal polyps in patients with FAP. However, because of the observed significantly increased CVD risk in clinical trials, celecoxib is not currently recommended for the primary prevention of $\mathrm{CRC}$ in general public [3].

\section{Statins}

Statins are a class of drugs that prevent coronary heart disease by reducing blood cholesterol and have gained traction as potential chemopreventive agent. Mechanistically, statins inhibit 3-hydroxy-3-methylglutaryl coenzyme A (HMG-CoA) reductase activity, which inhibits the conversion of HMG-CoA to mevalonate, reducing the amount of products downstream [27-29]. Products of the mevalonate pathway are important for different cellular functions, from cholesterol synthesis to the control of cell growth and differentiation. Observational studies have demonstrated that long term statin use has led to decreased incidence of gastrointestinal cancer, especially CRC and gastric cancer [30]. However, more randomized clinical trials must be conducted in order to corroborate statins' chemopreventive efficacy.

\section{Metformin}

Energy metabolism plays an essential role in cell proliferation, linking diabetes with elevated risks for several cancers [31]. From this association, metformin, a common drug for type II diabetes, was proposed as a chemopreventive drug for its anti-diabetic effects, which have potential value in prevention and therapy. Several meta-analyses have supported metformin's chemopreventive properties with lowered risks of cancer and mortality in diabetic patients who took metformin [32]. A 31\% decrease in overall cancer incidence and 34\% reduction in cancer mortality after adjusting for body mass index were observed for patients using metformin relative to those taking other anti-diabetic drugs [33]. Many clinical trials are ongoing to investigate the role of metformin in cancer treatment and prevention [34].

\section{IMIMUNOPREVENTION}

Genomic instability is a hallmark of cancer and is associated with immune response [35]. The unstable genomes of tumor cells acquire many mutational changes that produce tumor-specific antigens unique to the tumor genome, which are used as targets for the immune system [36]. Immunoprevention stimulates the immune system's recognition and response to tumor-specific antigens in order to prevent tumor onset or malignant transformation. Currently, the most successful implementations of immunoprevention are the human papillomavirus (HPV) and hepatitis B virus (HBV) vaccines for virally induced tumors [7]. Tumor-specific antigens are still being identified to engineer a vaccine for non-viral tumors. Oth- 
er forms of immunotherapy like immune checkpoint inhibitors have shown clinical potential in secondary prevention $[7,37]$. Table 2 summarizes the main immunopreventive agents that are discussed in this article.

\section{Vaccines against virally induced cancers}

Cancer preventive vaccines are utilized to stimulate the body's immune system to produce antibodies against foreign particles like viruses, making them effective agents in primary prevention of virus-induced cancers. HPV infection is the predominant risk factor for a number of cancers, including cervical, oropharyngeal, anal, penile, vulvar, and vaginal cancers [38], whereas HBV and hepatitis $\mathrm{C}$ virus are the major risk factors for hepatocellular carcinoma (HCC). Consequently, vaccines against HPV and HBV can prevent the development of virus-related cancers.

The carcinogenic mechanism of HPV infection mainly involves two oncoproteins, E6 and E7. E6 is responsible for degrading the $\mathrm{p} 53$ tumor suppressor gene, causing genetic instability and the buildup of DNA mutations that stimulate unrestrained cell proliferation [39]. E7 degrades retinoblastoma protein, a tumor suppressor that regulates $\mathrm{G} 1$ to $S$ phase transition, and pushes the cell cycle into the $S$ phase by overriding normal cell cycle checkpoints, leading to uncontrolled cell replication [40].

Currently, the HPV vaccines in clinical use include Cervarix, a bivalent vaccine which targets HPV16 and HPV18, the two most virulent types, Gardasil, a quadrivalent vaccine which targets HPV6/11/16/18, and Gardasil 9 vaccine, a 9-valent vaccine targeting HPV6/11/16/18/31/33/45/52/58. HPV vaccination has proven to be essential to the deterrence of HPV-related illnesses and prevention of HPV-related cancers. Australia was among the first countries to install a government-funded, universal HPV-vaccination program for its population in 2007, starting with 3 doses of Gardasil for 12to 13-year-old females and later expanding to 12- to 13-yearold males in 2013 [41]. Since then, significant decreases in HPV-related infections have emanated from school cohorts, showing a decline of $86 \%$ in 18 to 24 years old who received 3 doses and decline of $76 \%$ in those who received 1 to 2 doses. On a broader scale, vaccine trials conducted across North America, Europe, and Latin America demonstrated that almost $100 \%$ of women between 15 to 26 years of age developed antibodies corresponding to HPV 16 and 18 in one month after the third dosage of HPV vaccine, resulting in antibody levels ranging 10 to 104 times higher than that of normal infections $[42,43]$. The toxicity and side effects of the vaccine were minimal [41]. Given that HPV vaccination is both safe and effective, universal vaccination could lead to the eradication of cervical cancer. However, vaccination coverage remains low, and the distribution and funding of the vaccine for certain targeted demographic groups, of which adolescent girls are currently the priority, remains limited due to the economic, political, and cultural implications of vaccine implementation. Concerted, coordinated efforts globally are needed to increase HPV vaccine uptake.

Chronic HBV infection is a strong risk factor for HCC, hepatoma, and liver cirrhosis. In areas of high HBV prevalence, chronic HBV is responsible for $60 \%$ to $90 \%$ of all HCC in adults and almost $100 \%$ of HCCs in children [44]. The HBV virus persists as a "stealth virus" within the host cells by evading the immune system because of its subtle replication

Table 2. Summary of immunopreventive agents

\begin{tabular}{|c|c|c|c|}
\hline Agent & Target & Cancer preventive effect & References \\
\hline HPV vaccine & $\begin{array}{l}\text { Cervarix, a bivalent vaccine, targets } \\
\text { HPV } 16 / 18 \\
\text { Gardasil, a quadrivalent vaccine, targets } \\
\text { HPV 6/11/16/18 } \\
\text { Gardasil } 9 \text {, a } 9 \text {-valent vaccine, targets } \\
9 \text { types of HPV }\end{array}$ & $\begin{array}{l}\text { Prevents HPV-related cancers, including } \\
\text { cervical, anal, vulvar, vaginal, penile, } \\
\text { and oropharyngeal cancer }\end{array}$ & $38,40-43$ \\
\hline HBV vaccine & $\mathrm{HBV}$ & Prevents HBV-related liver cancer & $44-49$ \\
\hline MUC1 vaccine & MUC1 antigen & $\begin{array}{l}\text { MUC1 vaccine produced strong immune } \\
\text { response in patients with intestinal polyps } \\
\text { and in individuals at high risk for colon } \\
\text { cancer in Human clinical trials }\end{array}$ & $54-57$ \\
\hline HER2 vaccine & HER2 antigen & $\begin{array}{l}\text { Human clinical trials showed DCIS remission, } \\
\text { long-term production of Her2 antibodies, and } \\
\text { lost expression of Her2 }\end{array}$ & 58,59 \\
\hline \multirow{2}{*}{$\begin{array}{l}\text { Immune checkpoint } \\
\text { inhibitors (CLTA- } \\
4, \text { PD-1, PD-L1 } \\
\text { antibody) }\end{array}$} & \multirow[t]{2}{*}{$\begin{array}{l}\text { Immune checkpoint proteins } \\
\text { (CLTA-4, PD-1, PD-L1) }\end{array}$} & $\begin{array}{l}\text { Preclinical mouse models showed anti-PD-1 } \\
\text { treatment significantly prevented malignant } \\
\text { progression of oral premalignant lesions }\end{array}$ & $64-68$ \\
\hline & & $\begin{array}{l}\text { A case report showed anti-PD-1 inhibited the } \\
\text { development of new neoplasm in a Lynch } \\
\text { syndrome patient }\end{array}$ & 37 \\
\hline
\end{tabular}

HPV, human papillomavirus; HBV, hepatitis B virus; HER2, human epidermal growth factor receptor 2; DCIS, ductal carcinoma in situ; CLTA-4, cytotoxic T-lymphocyte-associated protein 4; PD-1, programmed cell death protein-1; PD-L1, programmed death ligand-1. 
methods. The viral DNA template remains in the nucleus while viral mRNA structures resemble that of host cell transcripts, and its own genome remains hidden within viral capsids that stay in the cytoplasm. These replication methods allow HBV to spread throughout host cells of the liver while avoiding immune detection. Exploiting the "memory" of the adaptive immune system, HBV vaccines provide immunity against further re-exposure to HBV by introducing a weakened, harmless virus resembling HBV into the body to induce and elevate Hepatitis B surface antigen (HBsAg)-specific antibody production [45].

HBV vaccines have proven to be effective through the analysis of vaccine implementation programs over the years. In 1984, Taiwan was the first region to implement a universal HBV vaccination program, which has persisted successfully for more than 2 decades [46]. The coverage rate of vaccination reached a high of $97 \%$. Infants were given 3 to 4 doses of $\mathrm{HBV}$ vaccine during their first week, and those born of highrisk mothers were treated to hepatitis immunoglobulin within 24 hours from their birth. Following 20 years after the program's initiation, chronic HBV infection rates have decreased significantly in the under-20 population from $10 \%$ to $17 \%$ to $0.7 \%$ to $1.7 \%$. Furthermore, the incidence rate of HCC decreased from 0.52 to 0.54 to 0.13 to 0.20 per 100,000 among the Taiwanese youth of 6 to 14 years of age. Currently, HBV vaccination has been administered in national immunization programs for children in 181 countries [47]. Hundreds of millions of HBV vaccinations have been given globally and have greatly reduced the disease burden, morbidity, and mortality of HBV-related illnesses wherever administered [48]. In developed countries, most infants and children are vaccinated with 3 doses of HBV vaccine with the first dose being within 24 hours of birth, and blood donors are screened for HBsAg. In addition, unvaccinated adults and adolescents of high risk groups are encouraged to receive the vaccine as well. However, the people of developing countries experience higher risks of HBV infection because their governments cannot afford the costs of acquiring and administering the vaccine [49]. Even though cancer vaccines have successfully prevented HBV and its carcinogenic predisposition to HCC, much remains to be accomplished to universalize the vaccine so that humankind, regardless of wealth or privilege, can become immune to the virus.

\section{Prevention for non-viral cancers}

Although HPV and HBV vaccines have successfully proven their immunopreventive effects against virally induced cancers, the vast majority of cancers cannot be traced to infectious agents. The progression of non-viral cancers from healthy tissue to malignant tumors involves years of mutational accumulations. For high-risk individuals, many opportunities for immunoprevention arise during the gradual oncogenic formation of non-viral cancers. Much research has been invested in engineering vaccines that can target non-viral can- cers. A challenging component of developing such vaccines is the identification of appropriate tumor-specific antigens to target. The optimal antigen should be expressed only in neoplastic cells or lesions, genetically altered during early stages of tumor formation, and essential to tumor survival. However, it is difficult to identify antigens that are both unique to tumors and altered in early stages. Few antigens are specific to only neoplastic or pre-neoplastic cells. The majority of target antigens are expressed to some degree among normal cells as well, making the physiological and biological role of the antigen important.

Numerous antigens have been suggested as candidates for their potential as immunopreventive vaccines based on their tumor specificity and ability to elicit an immune response [50]. In breast cancers associated with BRCA1 or BRCA2 mutations, recent studies have found a series of antigens including MAGE-A1, NYESO-1, CT10, and GAGE that were expressed in malignant breast tissue, but not in any normal breast tissue [7]. The overexpression and aberrant glycosylation of MUC1 antigen occur in pancreatic, breast, colon, and various other carcinomas. MUC1 mutations are also responsible for adenomatous polyps, dysplasia, and inflammatory bowl disease [51]. Mutated human epidermal growth factor receptor 2 (HER2) is another clear oncogene because the product of the HER2 gene is overexpressed in roughly $20 \%$ of invasive breast cancers and is associated with greater severity and worse survival [52].

In several animal models, the prophylactic nature of MUC1 vaccines was corroborated as the vaccines alleviated inflammatory bowel disease and prevented the development of inflammation-induced colon cancer [51]. Another mouse model showed that prophylactic administration of an anti-EGF receptor (anti-EGFR) vaccine reduced EGFR-driven lung cancer in mice by $76.4 \%$ [53]. In fact, many animal models have shown that the administration of non-viral antibodies could prevent tumor onset in healthy mice susceptible to cancer [54].

The first immunopreventive vaccine targeting non-viral cancers in human clinical trial was the MUC1 peptide vaccine in patients with intestinal polyps $[55,56]$. The results showed high production levels of tumor-specific, cytotoxic anti-MUC1 antibodies that induced the immune response. The vaccine was also tested in healthy individuals at high risk for colon cancer due to history of colon adenoma, and $43 \%$ of patients responded with strong and long-term immunity as indicated by high antibody levels [57]. For breast cancer immunoprevention, the promising target is the Her2 antigen. In a pilot clinical trial, 27 patients with ductal carcinoma in situ (DCIS) that overexpressed HER2 were administered the dendritic cell HER2 vaccine once a week for 4 weeks before surgery [58]. Upon surgery, 5 out 27 had no disease present, and 11 out of the 22 that still had DCIS experienced a decrease in lesion size and lost expression of HER2. HER2 antibodies were observed up to 52 months after initial vaccination. In an- 
other neoadjuvant clinical trial, vaccines comprised of autologous dendritic cells displaying HER2 peptides were administered to women with Her2 positive DCIS who were going to have surgery in 4-6 weeks [59]. By the time of surgery, $25 \%$ of patients experienced complete tumor regression, with the best rate being $38 \%$ among the ER-negative group.

Though clinical trials have shown promise, the use of immunopreventive vaccines in non-viral cancers comes with limitations and challenges [10]. Vaccines that target tumor-specific antigens are restricted to patients with pre-neoplastic lesions at high risk. These non-viral vaccines cannot be administered to healthy individuals because they may induce inflammatory responses and unnecessary toxicities. The use of single target vaccines may not be sufficient enough because tumors can overcome an immune response directed towards a single antigen. Therefore, the development of multivalent vaccines may be necessary for more effective immunopreventive effects in non-viral cancers.

\section{Immune checkpoint inhibitors}

In addition to using viral and non-viral vaccines to amplify the antitumor response, antibodies against immune checkpoints, such as the programmed death ligand-1 (PD-L1), programmed cell death protein-1 (PD-1), and cytotoxic T-lymphocyte-associated protein 4 (CTLA-4), work on the other end of the spectrum by inhibiting immunosuppressive mechanisms through which tumors evade immune detection.

To prevent autoimmunity, normal cells contain surface proteins that bind to "checkpoint" proteins on immune cells to switch them off so that the immune system does not target healthy cells. Cancer cells can adopt this same protective mechanism by producing surface proteins that bond with checkpoint proteins on immune cells to avoid being targeted by T-cells of the immune system.

The major checkpoints of the adaptive immune response include CTLA-4 and PD-1 receptors, which are both located on the surface of $T$ cells [60]. T cell activity occurs through the binding of the $T$ cell receptor (TCR) to antigens present on the major histocompatibility complex (MHC) located on the antigen-presenting cell (APC) surface [61]. T cell activation and proliferation requires co-stimulatory binding of its CD28 molecules with B7-1 or B7-2 molecules on the APC. CTLA-4 inhibits normal $T$ cell activity by competing against CD28 for B7-1 and B7-2 in the early stages of the adaptive immune response [62]. The CTLA-4 inhibitor prevents CTLA4 checkpoint protein from binding to B7 on APCs. By eliminating competitive inhibition brought about by CTLA-4:B7, CD28:B7 binding predominates. CD28:B7 and TCR bound to tumor-specific antigens on the MHC co-stimulate $\mathrm{T}$ cell activation and proliferation, inducing more potent antitumor response. An anti-CTLA-4 monoclonal antibody, Ipilimumab, was the first FDA-approved immune checkpoint inhibitor for cancer therapy [63].

PD-1 is another inhibitory transmembrane protein expressed on the surface of T cells and other immune cells [61]. Tumor cells express PD-L1 that binds to PD-1 on effector $T$ cells, weakening $T$ cell immune activity even though the TCR recognizes specific antigens on the MHC complex of the tumor cell. PD-1 and PD-L1 antibodies elicit antitumor response by preventing PD-1 and PD-L1 checkpoints from binding to each other (Fig. 2). Immune checkpoint inhibitors have revolutionized the treatment of many advanced stage cancer. Since the FDA approval of ipilimumab in 2011, six more checkpoint inhibitors have been approved for the treatment of various cancers, including PD-1 inhibitors nivolumab, pembrolizumab, cemiplimab and PD-L1 inhibitors atezolizum-

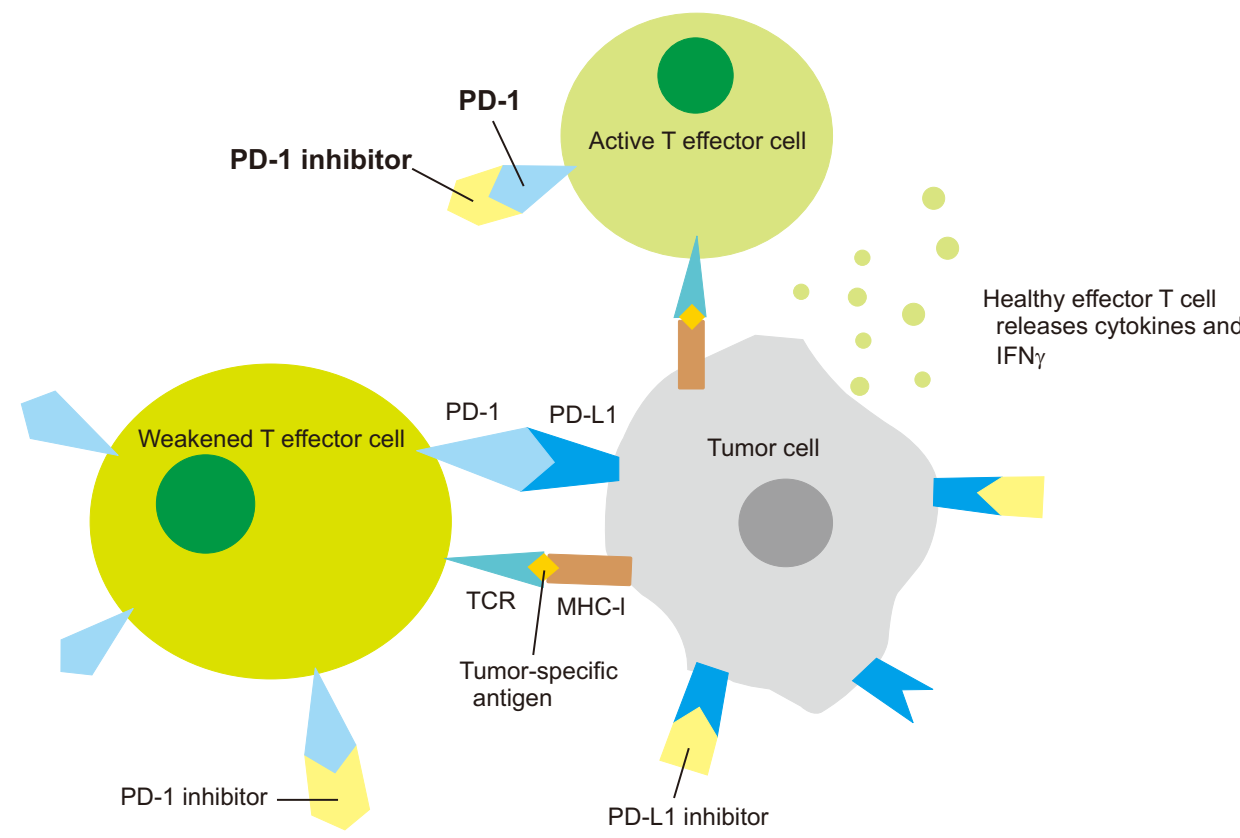

Figure 2. Mechanisms of programmed cell death protein-1 (PD-1) and programmed death ligand-1 (PD-L1) checkpoint inhibitors in immunotherapy and immunoprevention. $T$ cell activation occurs through the binding of the $T$ cell receptor (TCR) to antigens present on the major histocompatibility complex (MHC) located on APC (e.g., tumor cell) surface. PD-1 is an inhibitory transmembrane protein expressed on the surface of $T$ cells and other immune cells. PD-1 binds to its ligand PD-L1 on tumor cells and weakens $T$ cell immune activity (weakened $\mathrm{T}$ effector cells in the figure). PD-1 and PD-L1 inhibitors elicit antitumor response by preventing PD-1 and PD-L1 checkpoints from binding to each other, leading to active $T$ effector cells, cytokine release, and strong immune response. 
ab, avelumab, and durvalumab [63].

With the success of checkpoint inhibitors in immunotherapy of advanced stage cancers, utilizing anti-PD-1 and anti-PD-L1 as tools for secondary cancer prevention in preneoplastic lesions has generated considerable interests $[9,64-68]$. For example, in a preclinical mouse model of oral premalignant lesions (OPLs), anti-PD-1 treatment significantly prevented malignant progression of OPLs. OPLs responded to PD-1 blockade with significant increases of CD8+ and CD4+ effector $\mathrm{T}$ cells in their microenvironment, induction of IFN $\gamma$ and production of the T-cell effector granzyme B in tumor infiltrating cells, and induction of apoptosis in the epithelial cells of the OPLs, supporting the potential clinical application of immune checkpoint inhibitors in secondary prevention of OPL progression. In a recent case report, a patient with Muir-Torre syndrome, a variant of Lynch syndrome characterized by defective DNA mismatch repair and frequent gastrointestinal tumors and hyperplastic or neoplastic skin tumors, was treated with anti-PD-1 (pembrolizumab) immunotherapy as part of multi-modality treatment for his invasive bladder cancer. The patient previously had 136 cutaneous or visceral hyperplastic or neoplastic lesions within 19 years (mean 7.5 neoplasms/yr, range 2-20) prior to immunotherapy. The patient not only had a complete response of the bladder cancer, but also had an absence of new neoplasms during a 22-month follow-up period [37]. This study provides clinical support for using immune checkpoint inhibitors in cancer prevention settings.

\section{CONCLUSIONS AND FUTURE DIRECTIONS}

A number of chemopreventive agents have shown clear clinical efficacy in reducing cancer incidence among at-risk populations, including SERMs and Als in preventing breast cancer and aspirin in preventing CRC and other cancers. Observational studies have shown statins and metformin could reduce cancer incidence, but more randomized controlled clinical trials must be performed to substantiate the clinical efficacy of statins and metformin in cancer prevention. Nevertheless, the intake of these chemopreventive agents has been hampered by possible side effects of long-term use. Identifying high-risk individuals with a positive risk-benefit ratio is critical to enhance the uptake of chemoprevention. In the long run, new, more effective chemopreventive agents with fewer side effects need to be developed before chemoprevention can be more widely accepted.

Immunoprevention has risen to prominence in cancer research because the immune system is a living, adaptable entity that can be enhanced by vaccines and tumor-specific antigens to prevent tumor onset or control tumor growth. Currently, the most successful form of immunoprevention is cancer vaccine for virally induced cancers. HPV and HBV vaccines have significantly reduced the rates of HPV and HBV infection and their associated cancers. On the other hand, vaccines preventing non-viral cancers are still at the early stage of development, but clinical trials have shown promising immunopreventive effects in targeting tumor-specific antigens, such as MUC1 and Her2 in high-risk populations. In the future, additional specific tumor antigens are desired. In addition, it may be necessary to develop multivalent vaccines against multiple tumor antigens because of the heterogeneity of premalignant lesions, analogous to multivalent vaccines against HPV subtypes. Another potential benefit of multivalent vaccines targeting several tumor antigens is to reduce the occurrence of immune escaped precancerous clones.

Preclinical studies and case reports have supported the utility of immune checkpoint inhibitors, such as anti-CTLA-4 and anti-PD-1, as a secondary prevention modality to prevent malignant progression of preneoplastic lesions. Side effects would be a major concern for the application of checkpoint inhibitors in cancer prevention settings. Developing novel checkpoint blockers, identifying new immunotherapeutic targets, and preselecting persons with favorable with benefit-risk ratio based on biomarkers of efficacy and toxicity can help move immunoprevention field forward. Immunoprevention is likely to take the central stage in future cancer prevention given that our immune system contains billions of fighters that can be induced, enhanced, and manipulated to prevent the onset and progression of cancer.

\section{CONFLICTS OF INTEREST}

No potential conflicts of interest were disclosed.

\section{ORCID}

Kyle J. Gu, https://orcid.org/0000-0002-6672-6387

Guojun Li, https://orcid.org/0000-0001-9505-1502

\section{REFERENCES}

1. World Health Organization. Cancer. http://www.who.int/newsroom/fact-sheets/detail/cancer. Accessed June 5, 2020.

2. Siegel RL, Miller KD, Jemal A. Cancer statistics, 2020. CA Cancer J Clin 2020;70:7-30.

3. Maresso KC, Tsai KY, Brown PH, Szabo E, Lippman S, Hawk ET. Molecular cancer prevention: current status and future directions. CA Cancer J Clin 2015;65:345-83.

4. Meyskens FL Jr, Mukhtar H, Rock CL, Cuzick J, Kensler TW, Yang CS, et al. Cancer prevention: obstacles, challenges and the road ahead. J Natl Cancer Inst 2015;108:djv309.

5. Krstic MN, Mijac DD, Popovic DD, Pavlovic Markovic A, Milosavljević T. General aspects of primary cancer prevention. Dig Dis 2019;37:406-15.

6. Pruthi S, Heisey RE, Bevers TB. Chemoprevention for breast cancer. Ann Surg Oncol 2015;22:3230-5.

7. Finn OJ, Beatty PL. Cancer immunoprevention. Curr Opin Immunol 2016;39:52-8.

8. Wojtowicz ME, Dunn BK, Umar A. Immunologic approaches 
to cancer prevention-current status, challenges, and future perspectives. Semin Oncol 2016;43:161-72.

9. Palladini A, Landuzzi L, Lollini PL, Nanni P. Cancer immunoprevention: from mice to early clinical trials. BMC Immunol 2018;19:16.

10. Rao CV, Mohammed A, Asch AS, Janakiram NB. Immunoprevention of pancreatic cancer. Curr Med Chem 2018;25:2576-84.

11. Cuzick J, Forbes JF, Sestak I, Cawthorn S, Hamed H, Holli K, et al. Long-term results of tamoxifen prophylaxis for breast cancer-96-month follow-up of the randomized IBIS-I trial. J Natl Cancer Inst 2007;99:272-82.

12. Fisher B, Costantino JP, Wickerham DL, Cecchini RS, Cronin WM, Robidoux A, et al. Tamoxifen for the prevention of breast cancer: current status of the National Surgical Adjuvant Breast and Bowel Project P-1 study. J Natl Cancer Inst 2005;97:165262.

13. Fisher B, Costantino JP, Wickerham DL, Redmond CK, Kavanah M, Cronin WM, et al. Tamoxifen for prevention of breast cancer: report of the National Surgical Adjuvant Breast and Bowel Project P-1 Study. J Natl Cancer Inst 1998;90:1371-88.

14. Powles TJ, Ashley S, Tidy A, Smith IE, Dowsett M. Twenty-year follow-up of the Royal Marsden randomized, double-blinded tamoxifen breast cancer prevention trial. J Natl Cancer Inst 2007;99:283-90.

15. Veronesi U, Maisonneuve P, Rotmensz N, Bonanni B, Boyle $\mathrm{P}$, Viale G, et al. Tamoxifen for the prevention of breast cancer: late results of the Italian Randomized Tamoxifen Prevention Trial among women with hysterectomy. J Natl Cancer Inst 2007:99:727-37.

16. Nelson HD, Fu R, Zakher B, Pappas M, McDonagh M. Medication use for the risk reduction of primary breast cancer in women: updated evidence report and systematic review for the US Preventive Services Task Force. JAMA 2019;322:868-86.

17. Vogel VG, Costantino JP, Wickerham DL, Cronin WM, Cecchini $\mathrm{RS}$, Atkins JN, et al. Effects of tamoxifen vs raloxifene on the risk of developing invasive breast cancer and other disease outcomes: the NSABP Study of Tamoxifen and Raloxifene (STAR) P-2 trial. JAMA 2006;295:2727-41.

18. Vogel VG, Costantino JP, Wickerham DL, Cronin WM, Cecchini RS, Atkins JN, et al. Update of the National Surgical Adjuvant Breast and Bowel Project Study of Tamoxifen and Raloxifene (STAR) P-2 Trial: preventing breast cancer. Cancer Prev Res (Phila) 2010;3:696-706.

19. Goss PE, Ingle JN, Alés-Martínez JE, Cheung AM, Chlebowski RT, Wactawski-Wende J, et al. Exemestane for breastcancer prevention in postmenopausal women. N Engl J Med 2011;364:2381-91.

20. Cuzick J, Sestak I, Forbes JF, Dowsett M, Knox J, Cawthorn $\mathrm{S}$, et al. Anastrozole for prevention of breast cancer in high-risk postmenopausal women (IBIS-II): an international, double-blind, randomised placebo-controlled trial. Lancet 2014;383:1041-8.

21. Rothwell PM, Fowkes FG, Belch JF, Ogawa H, Warlow CP, Meade TW. Effect of daily aspirin on long-term risk of death due to cancer: analysis of individual patient data from randomised trials. Lancet 2011;377:31-41.

22. Rothwell PM, Wilson M, Elwin CE, Norrving B, Algra A, Warlow $\mathrm{CP}$, et al. Long-term effect of aspirin on colorectal cancer incidence and mortality: 20-year follow-up of five randomised trials. Lancet 2010;376:1741-50.

23. Thorat MA, Cuzick J. Role of aspirin in cancer prevention. Curr Oncol Rep 2013;15:533-40.

24. Benamouzig R, Uzzan B, Martin A, Deyra J, Little J, Girard B, et al. Cyclooxygenase-2 expression and recurrence of colorectal adenomas: effect of aspirin chemoprevention. Gut 2010;59:622-9.

25. Chan AT. COX-2 expression in adenoma: an imperfect marker for chemoprevention. Gut 2010;59:568-9.

26. Bibbins-Domingo K; U.S. Preventive Services Task Force Aspirin use for the primary prevention of cardiovascular disease and colorectal cancer: U.S. Preventive Services Task Force recommendation statement. Ann Intern Med 2016;164:836-45.

27. Boudreau DM, Yu O, Johnson J. Statin use and cancer risk: a comprehensive review. Expert Opin Drug Saf 2010;9:603-21.

28. Gazzerro P, Proto MC, Gangemi G, Malfitano AM, Ciaglia E, Pisanti S, et al. Pharmacological actions of statins: a critical appraisal in the management of cancer. Pharmacol Rev 2012;64:102-46.

29. Gronich N, Rennert G. Beyond aspirin-cancer prevention with statins, metformin and bisphosphonates. Nat Rev Clin Oncol 2013;10:625-42

30. Lytras T, Nikolopoulos G, Bonovas S. Statins and the risk of colorectal cancer: an updated systematic review and metaanalysis of 40 studies. World J Gastroenterol 2014;20:1858-70.

31. Suh S, Kim KW. Diabetes and cancer: cancer should be screened in routine diabetes assessment. Diabetes Metab $\mathrm{J}$ 2019;43:733-43

32. Morales DR, Morris AD. Metformin in cancer treatment and prevention. Annu Rev Med 2015;66:17-29.

33. Decensi A, Puntoni M, Goodwin P, Cazzaniga M, Gennari A, Bonanni B, et al. Metformin and cancer risk in diabetic patients: a systematic review and meta-analysis. Cancer Prev Res (Phila) 2010;3:1451-61

34. Romero R, Erez O, Hüttemann M, Maymon E, Panaitescu $\mathrm{B}$, Conde-Agudelo A, et al. Metformin, the aspirin of the $21 \mathrm{st}$ century: its role in gestational diabetes mellitus, prevention of preeclampsia and cancer, and the promotion of longevity. Am J Obstet Gynecol 2017;217:282-302.

35. Subbiah V, Kurzrock R. The marriage between genomics and immunotherapy: mismatch meets its match. Oncologist 2019;24:1-3.

36. Andrews MC, Wargo JA. Cancer evolution during immunotherapy. Cell 2017:171:740-2.

37. Mancuso JG, Foulkes WD, Pollak MN. Cancer immunoprevention: a case report raising the possibility of "immuno-interception". Cancer Prev Res (Phila) 2020;13:351-6.

38. Bosch FX, Broker TR, Forman D, Moscicki AB, Gillison ML, Doorbar J, et al. Comprehensive control of human papillomavirus infections and related diseases. Vaccine 2013;31 Suppl 7:H1-31. 
39. Mantovani F, Banks L. The human papillomavirus E6 protein and its contribution to malignant progression. Oncogene 2001;20:7874-87.

40. Boyer SN, Wazer DE, Band V. E7 protein of human papilloma virus-16 induces degradation of retinoblastoma protein through the ubiquitin-proteasome pathway. Cancer Res 1996;56:4620-4.

41. Lee LY, Garland SM. Human papillomavirus vaccination: the population impact. F1000Res 2017;6:866.

42. Harper DM, Franco EL, Wheeler C, Ferris DG, Jenkins D, Schuind A, et al. Efficacy of a bivalent L1 virus-like particle vaccine in prevention of infection with human papillomavirus types 16 and 18 in young women: a randomised controlled trial. Lancet 2004;364:1757-65.

43. Harper DM, Franco EL, Wheeler CM, Moscicki AB, Romanowski $B$, Roteli-Martins CM, et al. Sustained efficacy up to 4.5 years of a bivalent L1 virus-like particle vaccine against human papillomavirus types 16 and 18: follow-up from a randomised control trial. Lancet 2006;367:1247-55.

44. Chang MH. Cancer prevention by vaccination against hepatitis B. Recent Results Cancer Res 2009;181:85-94.

45. Webster GJ, Reignat S, Brown D, Ogg GS, Jones L, Seneviratne $\mathrm{SL}$, et al. Longitudinal analysis of CD8+ T cells specific for structural and nonstructural hepatitis $B$ virus proteins in patients with chronic hepatitis B: implications for immunotherapy. J Virol 2004;78:5707-19.

46. $\mathrm{Ni} \mathrm{YH}$, Chen DS. Hepatitis B vaccination in children: the Taiwan experience. Pathol Biol 2010;58:296-300.

47. Romanò L, Paladini S, Galli C, Raimondo G, Pollicino T, Zanetti AR. Hepatitis B vaccination. Hum Vaccin Immunother 2015;11:53-7.

48. Zanetti AR, Van Damme P, Shouval D. The global impact of vaccination against hepatitis $B$ : a historical overview. Vaccine 2008;26:6266-73.

49. Thun MJ, DeLancey JO, Center MM, Jemal A, Ward EM. The global burden of cancer: priorities for prevention. Carcinogenesis 2010;31:100-10.

50. Cheever MA, Allison JP, Ferris AS, Finn OJ, Hastings BM, Hecht $\mathrm{TT}$, et al. The prioritization of cancer antigens: a national cancer institute pilot project for the acceleration of translational research. Clin Cancer Res 2009;15:5323-37.

51. Vlad AM, Kettel JC, Alajez NM, Carlos CA, Finn OJ. MUC1 immunobiology: from discovery to clinical applications. Adv Immunol 2004;82:249-93.

52. Moasser MM, Krop IE. The evolving landscape of HER2 targeting in breast cancer. JAMA Oncol 2015;1:1154-61.

53. Ebben JD, Lubet RA, Gad E, Disis ML, You M. Epidermal growth factor receptor derived peptide vaccination to prevent lung adenocarcinoma formation: an in vivo study in a murine model of EGFR mutant lung cancer. Mol Carcinog 2016;55:1517-25.

54. Lollini PL, Nicoletti G, Landuzzi L, Cavallo F, Forni G, De Giovanni C, et al. Vaccines and other immunological approaches for cancer immunoprevention. Curr Drug Targets 2011;12:1957-
73.

55. Kimura T, McKolanis JR, Dzubinski LA, Islam K, Potter DM, Salazar AM, et al. MUC1 vaccine for individuals with advanced adenoma of the colon: a cancer immunoprevention feasibility study. Cancer Prev Res (Phila) 2013;6:18-26.

56. Lohmueller JJ, Sato S, Popova L, Chu IM, Tucker MA, Barberena $\mathrm{R}$, et al. Antibodies elicited by the first non-viral prophylactic cancer vaccine show tumor-specificity and immunotherapeutic potential. Sci Rep 2016;6:31740.

57. Beatty PL, Narayanan S, Gariépy J, Ranganathan S, Finn OJ. Vaccine against MUC1 antigen expressed in inflammatory bowel disease and cancer lessens colonic inflammation and prevents progression to colitis-associated colon cancer. Cancer Prev Res (Phila) 2010;3:438-46.

58. Sharma A, Koldovsky U, Xu S, Mick R, Roses R, Fitzpatrick E, et al. HER-2 pulsed dendritic cell vaccine can eliminate HER2 expression and impact ductal carcinoma in situ. Cancer 2012;118:4354-62.

59. Fracol M, Xu S, Mick R, Fitzpatrick E, Nisenbaum H, Roses R, et al. Response to HER-2 pulsed DC1 vaccines is predicted by both HER-2 and estrogen receptor expression in DCIS. Ann Surg Oncol 2013;20:3233-9.

60. Conway JR, Kofman E, Mo SS, Elmarakeby H, Van Allen E. Genomics of response to immune checkpoint therapies for cancer: implications for precision medicine. Genome Med 2018;10:93.

61. Buchbinder EI, Desai A. CTLA-4 and PD-1 pathways: similarities, differences, and implications of their inhibition. Am J Clin Oncol 2016;39:98-106.

62. Krummel MF, Allison JP. CD28 and CTLA-4 have opposing effects on the response of $\mathrm{T}$ cells to stimulation. J Exp Med 1995;182:459-65.

63. Vaddepally RK, Kharel P, Pandey R, Garje R, Chandra AB. Review of indications of FDA-approved immune checkpoint inhibitors per NCCN guidelines with the level of evidence. Cancers (Basel) 2020;12:738.

64. Levingston CA, Young MR. Transient immunological and clinical effectiveness of treating mice bearing premalignant oral lesions with PD-1 antibodies. Int J Cancer 2017;140:1609-19.

65. Levingston CA, Young MRI. Local immune responsiveness of mice bearing premalignant oral lesions to PD-1 antibody treatment. Cancers (Basel) 2017;9:62.

66. Wang J, Xie T, Wang B, William WN Jr, Heymach JV, EINaggar AK, et al. PD-1 blockade prevents the development and progression of carcinogen-induced oral premalignant lesions. Cancer Prev Res (Phila) 2017;10:684-93.

67. Willis JA, Reyes-Uribe L, Chang K, Lipkin SM, Vilar E. Immune activation in mismatch repair-deficient carcinogenesis: more than just mutational rate. Clin Cancer Res 2020;26:11-7.

68. Chen Y, Li Q, Li X, Ma D, Fang J, Luo L, et al. Blockade of $\mathrm{PD}-1$ effectively inhibits in vivo malignant transformation of oral mucosa. Oncoimmunology 2017;7:e1388484. 